\title{
Designing Excellent Supply Chain Network in Uncertainty Environment with Fuzzy Logic
}

\author{
Mostafa Maleki Someah Lu (Corresponding author) \\ MSc Student, Department of Industrial Management, Islamic Azad University (IAU) \\ Qazvin branch, Qazvin, Iran \\ Tel: 98-21-4891-4435Ｅ-mail: Mostafa9531@Gmail.com
}

\author{
Alireza Irajpour \\ Assistant professor, Department of Industrial Management, Islamic Azad University (IAU) \\ Qazvin branch, Qazvin, Iran \\ Tel: 98-28-1366-5275Ｅ-mail: aerajpour@yahoo.com
}

\author{
Naser Hamidi \\ Assistant professor, Department of Industrial Management, Islamic Azad University (IAU) \\ Qazvin branch, Qazvin, Iran \\ Tel: 98-28-1366-5275Ｅ-mail: Nhamidi1344@gmail.com \\ Reza Kiani Mavi \\ Assistant professor, Department of Industrial Management, Islamic Azad University (IAU) \\ Qazvin branch, Qazvin, Iran \\ Tel: 98-28-1366-5275 E-mail: rezakianimavi@yahoo.com
}

Received: September 26, $2010 \quad$ Accepted: October 11, $2010 \quad$ doi:10.5539/ijbm.v6n4p241

\begin{abstract}
In today's global marketplace, individual firms do not compete as independent entities rather as an integral part of a supply chain. Therefore, coordination and integration of key business activities undertaken by an enterprise, is of greatest value. For succeed in this competitive world, organizations must focus on their excellence position from EFQM perspective. This paper proposes a fuzzy mathematical programming model for supply chain planning which considers excellence score, geographical score and capacity of each supplier and manufacturer and distributor. The model has been formulated as a fuzzy mixed-integer linear programming model where some data are fuzzy and modeled by triangular fuzzy numbers. This paper has been done in Sazeh Gostar Saipa Company in Iran. This company supplies required automobile parts for SAIPA manufacturing group. Results show that this model can be applied for designing excellent supply chain network and has significant managerial implications.
\end{abstract}

Keywords: Fuzzy mathematical programming, Supply chain planning, Supply chain network, Optimization, EFQM

\section{Introduction}

Today, the success measures for the companies are thought as lower costs, shorter production time, shorter lead time, less stock, larger product range, more reliable delivery time, better customer services, higher quality, and providing the efficient coordination between demand, supply and production. For this reason, supply chain management (SCM) concept is occurred and, SCM has become an important necessity (Gumus, et al., 2009). A supply chain (SC) is an integrated process where a number of business entities (including suppliers, manufacturers, distributors, and retailers) work together to convert raw materials into the specified finished 
products and deliver these finished products to retailers or customers. Managing a SC effectively to fulfill the customer service levels is very difficult, since various sources of uncertainty and complex interrelationships at various levels between various entities exist in the SC (Wanga and Shub, 2005). The SC includes inventories and production facilities between them. It is assumed that the SC operates in an uncertain environment. Uncertainty is associated with: (1) customer demand, (2) supply deliveries along the SC and (3) external or market supply. Uncertainties are described by vague and imprecise phrases that are interpreted and represented by fuzzy sets (Petrovic, et al., 1999). The design of SC networks is a difficult task because of the intrinsic complexity of the major subsystems of these networks and the many interactions among these subsystems, as well as external factors such as the considerable uncertainty in product demands (Gumus, et al., 2009). An efficient integration of production and distribution plans into a unified framework is critical to achieving competitive advantage. Supply chain is a dynamic network of several business entities that involve a high degree of imprecision. Most studies have focused on traditional analytical and heuristic methods to model the SC network planning problem. A few studies have attempted to model the problem in a fuzzy environment (Bilgen, 2010).

With regarding much complexity and change-ability of the global environment, most of variables are not crisp and they are fuzzy. Variables such as demand, price exchange, capacity and so on, are a few to say. This paper emphasized on strategic programming that contains programming of supply chain based on fuzzy logic and expands to its design. Simply designing of supply chain network (SCN) is containing excellent compositional identification of suppliers, manufactures and distributors that clears special compound of customers demand. In this paper fuzzy mathematical programming is developed for designing excellent supply chain model.

The reminder of paper is organized as follow. Section 2 presents a literature review of supply chain management and its planning by fuzzy mathematical models and EFQM, briefly. In section 3, the proposed methodology for optimizing SCN is developed. Section 4 illustrates a numerical example. Finally, concluding remarks and suggestion for future studies are proposed.

\section{Literature review}

Many companies have been trying to optimize their production and distribution systems separately, but using this approach limits any possible increase in profit. Some papers propose a solution for integrated production and distribution planning in complicated environments where the objective is to maximize the total profit. These papers state that the supply chain environment requires a production-distribution planning system to enable collaboration between production and distribution units and confirm the substantial advantage of the integrated planning approach over the decoupled one (Aliev, et al., 2007). In the face of today's highly competitive and global markets, and constant pressure to reduce lead times, enterprises consider supply chain management (SCM) to be the key area for improvement. As such, the ultimate success of a firm will depend on its managerial ability to integrate and coordinate the intricate network of business relationships among SC partners. Thus, in addition to having good internal management and controls, companies should be oriented toward maintaining good strategic partners and collaboration (Selim, et al., 2008). The supply chain is an integrated process wherein a number of business entities (suppliers, manufacturers, distributors and retailers) work together in an effort to acquire raw materials, convert them into specified final products and deliver these final products to retailers. The supply chain further fosters a new concept in management: the concept of supply chain management (Chen, et al., 2007).

In today's world, enterprises have to cope with the growing markets and with the increasing customer expectations. Because of the customer expectations about obtaining the products at the right time and quantity, and besides this the improvements against the risks created by the sudden fluctuations in local and global economies, companies need to analyze their working styles (Gumus, et al., 2009). Modeling SCM by mathematical programming is an innovative and popular issue. When looking back into the fuzzy modeling, e.g., developing the fuzzy evaluation system to measure supply chain (SC) performance, selecting the vendor by fuzzy approach, managing the inventory level by fuzzy supply and demand, deciding the stock policy by fuzzy inventory cost, optimizing the schedule and distribution, using fuzzy logic to develop an intelligent agent for SCM, and applying the fuzzy multi-objective approach to solve the production/distribution network in a SC are significant areas (Wen, et al., 2010). Uncertainty is one of the main characteristics of systems which are associated with customers. Researchers believe that the main reason for uncertainty in a SC is its dynamism and states that a multi level SC is subject to a great deal of uncertainty due to its sets of service providers and the existence of uncertainties of elements in each level. This high level of uncertainty reduces SCM abilities to predict future conditions. For example, uncertainty as to the amount of order or customers' demand and corresponding supply time are just a few to name (Hanafizadeh and Sherkat, 2009). 
Lee and Billington (1993) present an operational model for material management and inventory control in uncentralize supply chain. Arentzen, et al. (1995) present Global supply chain model (GSCM) for designing manufacture network, distribute and sale. Integer compositional lineal programming model for decrease of cost and/or balanced aggregated production and distribute times is with consideration of variety limitations in demand and capacity limitations. Talluri, et al. (1999) offered a frame base on Data envelopment Analysis (DEA) and multi-scale decision for designing of supply chain network. Tallory and baker (2002) Whit use of integer programming and DEA Analysis technical for and present a multi-stage model take action for skilled supply chain programming. Behagovat and sharma (2007) used Balance Scorecard (BSC) for assessment evaluation of supply chain management.

Peidro, et al. (2009) propose a fuzzy mathematical programming model for supply chain planning which considers supply, demand and process uncertainties. Wanga and Shub (2005) develop a fuzzy decision methodology to handle SC uncertainties and to determine SC inventory strategies, while there is lack of certainty in data or even lack of available historical data. Fuzzy set theory is used to model SC uncertainty. Wen, et al. (2010) formulated a game framework for the investigation of strategic behavior of supply chain partners based on fuzzy multi-objective programming, the alliance matrix and achievement level/aspiration degree. Gumus, et al. (2009) developed an integrated supply chain (SC) design model and a SC network design case was examined for a reputable multinational company in alcohol free beverage sector. Peidro, et al. (2010) modeled supply chain (SC) uncertainties by fuzzy sets and develops a fuzzy linear programming model for tactical supply chain planning in a multi-echelon, multi-product, multi-level, multi-period supply chain network.

Bilgen (2010) addresses the production and distribution planning problem in a supply chain system that involves the allocation of production volumes among the different production lines in the manufacturing plants, and the delivery of the products to the distribution centers. An integrated optimization model for production and distribution planning is proposed, with the aimed of optimally coordinating important and interrelated logistics decisions. A real supply chain operates in a highly dynamic and uncertain environment.

Gumus, et al. (2009) for effective multi-echelon supply chains under stochastic and fuzzy environments, an inventory management framework and deterministic/stochastic-neuro-fuzzy cost models within the context of this framework are structured. Zhou, et al. (2008) assumed that the supply chain is operated in a fuzzy environment. The fuzziness is associated with the customer's demand and the manufacturing cost. Two different game structures of the supply chain are considered: the manufacturer and the retailer cooperate with each other and behave as an integrated-firm; the manufacturer behaving as a Stackelberg leader dominates the supply chain. The SC fuzzy model described in (Petrovic, et al., 1999) is developed to determine the order quantities for each inventory in the SC in the presence of uncertainties that give an acceptable service level of the SC at reasonable total cost. Liang and Cheng (2009) applied fuzzy sets to integrating manufacturing/distribution planning decision (MDPD) problems with multi-product and multi-time period in supply chains by considering time value of money for each of the operating cost categories. Liang (2008) develops a fuzzy multi-objective linear programming (FMOLP) model with piecewise linear membership function to solve integrated multi-product and multi-time period production/distribution planning decisions (PDPD) problems with fuzzy objectives. In order to reflect the collaborative planning issues to the model and to provide a more realistic model structure, decision makers' imprecise aspiration levels for the goals are incorporated into the model using fuzzy goal programming approach in Selim, et al.(2008).

$\mathrm{Xu}$ and Zhai (2008) proposed an optimal technique for dealing with the fuzziness aspect of demand uncertainties. Wang (2009) seeks to find methods to address traditional DRP's (Distribution Requirement Planning) weaknesses and to improve the performances of DRP systems. Kim, et al. (2010) developed a framework for assessing the comprehensive performance of supply chain partnership (SCP). They focused on developing a framework that could be implemented not only in entire supply chains but also in a dyadic relationship. To achieve the objective, they developed the framework by using the basic structure of the EFQM model.

\subsection{The EFQM Excellence Model}

The EFQM Excellence Model was created in 1991 by the European Foundation for Quality Management $(E F Q M)$ as a framework against which applicants for the European Quality Award are judged, and to recognize organizational excellence in European companies. The EFQM Excellence Model is made up of nine elements grouped under five enabler criteria (leadership, policy and strategy, people, partnerships and resources and processes) and four result criteria (people results, customer results, society results and key performance results) (Fig. 1). The enablers represent the way the organization operates, and the results concentrate on achievements relating to organizational stakeholders. The meaning of each criterion is summarized in (Table 1). 
Each criterion is broken down into several sub-criteria and each sub-criterion is illustrated with various "guidance points" exemplifying what the organization has to do in order to develop the criteria (bou-liusar, et al., 2009).

The EFQM Excellence Model is based on the logical assumption that there is an internal structure between the enabler criteria, which could be expressed as follows: leadership drives policy and strategy, people management and partnerships and resources, and these three elements influence the results through suitable processes. Another definition of the model suggests that excellent results with respect to performance, customers, people and society are achieved through leadership, driving policy and strategy, partnerships and resources, and processes. This balanced approach allows the synergies between the elements of the model to be optimized, which is in accordance with the global orientation postulated by the model. A balanced development implies an enabler internal structure, according to which the maximum improvement in the results is obtained only when the contributions of all enablers are the same (Haffer and Kristensen, 2010).

This paper is based on the concept of continuous improvement and Deming PDCA circle (Plan, Do, Check \& Action) that is one of important tools of quality control and continuous improvement.

\section{Proposed methodology for designing Excellent SCN}

Here, we propose a there phase methodology for the purpose of the paper (Fig. 2).

Phase 1: In this phase, potential suppliers, manufacturers and distributors are assessed for determining their excellence score. This score is an indicator of their position from EFQM viewpoint.

Phase 2: After initial recognition of potential suppliers, manufacturers and distributors in phase 1, in this stage by applying a fuzzy integer programming model whit capacity constraints and fuzzy demand, we can identify final suppliers, manufacturers and distributors.

Identification of potentials suppliers/

3.1 Proposed mathematical model for selecting final suppliers, manufacturers \& distributors (Model n.1)

$$
\sum_{i=1}^{n} x_{1} \underset{\infty}{\infty} z
$$

s.t:

$$
\begin{aligned}
& \sum_{i=1}^{n} E_{1} x_{1}-E_{\text {avg }}\left(\sum_{i=1}^{n} X_{i}\right) \geq 0 \\
& \sum_{f=1}^{n} y_{1} x_{1}-Y_{a x g}\left(\sum_{f=1}^{n} x_{1}\right) \geq 0 \text {. } \\
& \sum_{1=1}^{\text {II }} v_{1} x_{1} \Rightarrow v_{\text {miln }}
\end{aligned}
$$

$\mathrm{Xi}=0$ or $1 \quad \mathrm{i}=1,2 \ldots \mathrm{n}$

$\mathrm{Xi}$ : Selection or not of unit $\mathrm{i}$

Ei: Excellence score of unit i, determined in phase 1.

Yi: Location score of unit i

Vi: Maximum capacity of unit i

$\mathrm{V}_{\text {min }}$ : Minimum amount of demand that must be met

The above model is separately solved for each of three business processes (suppliers, distributors and manufacturers). The solution is optimum number of suppliers, manufacturers and distributors in supply chain network.

Phase 3: After optimizing the number of suppliers, manufacturers and distributors in SCN (phase 2), in phase 3 for minimizing total cost of SCN we should identify initial development plan. This plan includes determining the optimal amount of parts and materials that flow between suppliers, manufacturers and distributors. 
Suppose that "p" is number of suppliers, "q" is number of manufacturers and " $r$ " is number of selected distributors in phase 2 , so figure 3 indicates the scenario of transporting parts and materials between suppliers, manufacturers and distributors (Fig. 3).

3.2 Proposed transportation programming model for designing SCN is as follow. (Model n.2)

$$
\sum_{i=1}^{E} \sum_{i=1}^{n} c_{i \mid} x_{||}+\sum_{i=1}^{n} \sum_{k=1}^{x} c_{\mid k} x_{\mid k}
$$

s.t:

$$
\begin{aligned}
& \Sigma_{j=1}^{q} x_{i j} \leq U_{i} \quad \forall_{i} \\
& \sum_{\mathrm{i}=1}^{\mathrm{p}} \mathrm{X}_{1 \mathrm{j}} \leq \mathrm{U}_{\mathrm{i}} \quad \forall_{1} \\
& \sum_{1=1}^{n} x_{11}-\sum_{k=1}^{n} x_{1 k}=0 \quad \forall 1 \\
& \sum_{k=1}^{4} x_{l k} \geqslant x v_{k} \quad v_{k} \\
& X_{i j} \geq 0 \quad \forall_{i j} \\
& X_{F} \geq 0 \quad \forall / \mathrm{k}
\end{aligned}
$$

Cij: Cost of transporting one unit from supplier $\mathrm{i}$ to manufacturer $\mathrm{j}$

Xij: Number of units that transported from supplier i to manufacturer $j$

Cjk: Costs of transporting one unit from manufacturer $\mathrm{j}$ to distributor $\mathrm{k}$

$\mathbf{X j k}$ : Number of units that transported from manufacturer $\mathbf{j}$ to distributor $\mathrm{k}$

Ui: Capacity of supplier i

Uj: Capacity of manufacturer $\mathrm{j}$

$\mathbf{V}_{\mathbf{k}}$ : Demand of distributor $\mathrm{k}$

\section{Numerical example}

For running model 1, we use data of with given excellence and location score and their fuzzy capacity (Tables 2-5).

We used relation for defyzzying the fuzzy capacity. $\left[S\left(a_{1}, a_{2}, a_{3}\right)=\left(a_{1}+2 a_{2}+a_{3}\right) / 4\right]$ (Fig. 4).

If we suppose unique fuzzy demand $(2100,2500,2800)$ for every distributor, then optimum amount of transportation between suppliers and manufacturers and also between manufacturers and distributors is identified as shown in (Table 6).

This paper has been done in Sazeh Gostar Saipa Company in Iran. This company supplies required automobile parts for SAIPA manufacturing group (OEM). SAIPA is one of the largest automobile manufacturers in Middle East. It has over 25000 employees and workers. It produces about 700000 automobiles annually.

We run data with Lingo software and select supplier's number of $7 \& 9$, manufacturer's numbers of $19 \& 20$ and distributor number of 3 . (Note 1).

Hatched cells show the cost of transporting one unit from origin to destination. According to table 6 , for example 1273 units must be transported from manufacturer 20 to distributor 3(Note 1). 


\section{Conclusion}

The proposed model in this paper has important managerial implications. It can help mangers to design excellent SCN by regarding organization excellence, geographical location and transportation issues while traditional models focused on identifying optimal network. From managerial viewpoint, integrating these factors in designing SCN leads to lower cost, on-time delivery, high quality service and more satisfaction of customers.

In this paper it is supposed that all suppliers supply all required parts and materials for finished products while in real word different suppliers supply different parts. In practice, suppliers should be assessed according to industry type, technology used and so on. In this paper, we assume that one unit of each part is used for producing a product while this assumption not applicable in reality. Therefore, we suggest that future researches focus on this point. That is, they can extend models 1,2 for situations that different units of parts are used in a product. In addition, some of candidates were deleted in phase 1 for their more cost.

By implementing the proposed method, we acquire cast reduction which is $1.7 \$$ per tire in Kia-pride (about 1.19 million\$ in year). 12 suppliers have informed to Sazeh Gostar Saipa Company that they have prepared themselves for EFQM assessment. Penalties, which are related to suppliers delay, decreased to 2 cases if we want compare with the same period in previous 6 months. Sazeh Gostar Saipa Company agreed with results and announces that they are going to implementing the model on other suppliers.

Future studies can extend model 1 for the situation that some candidates inevitably must be selected and considered in next phases.

\section{References}

Aliev, R.A., Fazlollahi, B., Guirimov, B.G., \& Aliev, R.R. (2007). Fuzzy-genetic approach to aggregate production-distribution planning in supply chain management. Information Sciences, 177(20), 4241-4255.

Arntzen, B.C., Brown, G.G., Harrision, T.P., \& Trafton, L.L. (1995). Global supply chain management at digital equipment corporation. Interfaces, 25 (1), 69-93.

Bhagwata, R., \& Sharma, M.K. ( 2007). Performance measurement of supply chain management: A balanced scorecard approach. Computers \& Industrial Engineering, 53(1), Pages 43-62.

Bilgen, B. (2010). Application of fuzzy mathematical programming approach to the production allocation and distribution. Supply chain network problem Expert Systems with Applications, 37(6), 4488-4495.

Bou-Llusar, J.C., Escrig-Tena, A.B., \& Roca-Puig, V. (2009). An empirical assessment of the EFQM Excellence Model: Evaluation as a TQM framework relative to the MBNQA Model. Journal of Operations Management, 27, $1-22$.

Chen, C.L., Yuan, T.W., \& Lee, W.C. (2007). Multi-criteria fuzzy optimization for locating warehouses and distribution centers in a supply chain network. Journal of the Chinese Institute of Chemical Engineers, 38, 393-407.

Gumus, A.T., \& Guneri, A.F. (2009). A multi-echelon inventory management framework for stochastic and fuzzy Supply chains. Expert Systems with Applications, 36, 5565-5575.

Gumus, A.T., Guneri, A.F., \& Keles S. (2009). Supply chain network design using an integrated neuro-fuzzy and MILP approach: A comparative design study. Expert Systems with Applications, 36, 12570-12577.

Haffer, F., \& Kristensen, K. (2010). People management as indicator of business excellence: the Polish and Danish perspectives. The TQM Journal, 22 (4), 386-398.

Hanafizadeh, P., \& Sherkat, M.H. (2009). Designing fuzzy-genetic learner model based on multi-agent systems in supply chain management. Expert Systems with Applications, 36(6), 10120-10134.

Kim, D.Y. (2010). Performance assessment framework for supply chain partnership. Supply Chain Management: an International journal, 15(3), 187-195.

Lee, H.L., \& Billington, C. (1993). Material management in decentralized supply chains. Operations Research, $41(5), 835-847$.

Liang, T.F. (2008). Fuzzy multi-objective production/distribution planning decisions with multi-product and multi-time period in a supply chain. Computers \& Industrial Engineering, 55, 676-694.

Liang, T.F., \& Cheng, H.W. (2009). Application of fuzzy sets to manufacturing/distribution planning decisions with multi-product and multi-time period in supply chains. Expert Systems with Applications: an International journal, 36, 3367-3377. 
Peidro, D., Mula, J., Jiménez, M., \& Botella, M.D.M. (2010). Production, Manufacturing and Logistics A fuzzy linear programming based approach for tactical supply chain planning in an uncertainty environment. European Journal of Operational Research, 205, 65-80.

Peidro, D., Mulaa, J., Polera, R., \& Verdegayb, J.L. (2009). Fuzzy optimization for supply chain planning under supply, demand and process uncertainties. Fuzzy Sets and Systems, 160, 2640-2657.

Petrovic, D., Roy, R., \& Petrovic, R. (1999). Supply chain modeling using fuzzy sets. International journal of Production Economics, 59, 443- 453.

Selim, H., Araz, C., \& Ozkarahan, I. (2008). Collaborative production-distribution planning in supply chain: A fuzzy goal programming approach. Transportation Research, 44(3), 396-419.

Talluri, S., \& Baker, R.C. (2002). A multi-phase mathematical programming approach for effective supply chain design. European Journal of Operational Research, 141(3), 544-558.

Talluri, S., \& Baker, R.C., Sarkis, J. (1999). A framework for designing efficient value chain networks. International Journal of Production Economics, 62 (1-2), 133-144.

Wang, J.L. (2009). A supply chain application of fuzzy set theory to inventory control models - DRP system analysis. Expert Systems with Applications: an international journal, 36, 9229-9239.

Wanga, J., \& Shub, Y.F. (2005). Fuzzy decision modeling for supply chain management. Fuzzy Sets and Systems, $150,107-127$.

Wen, C.Y., Larbani, M., \& Hao, L. C. (2010). Simulation of supply chain game with multiple fuzzy goals. Fuzzy Sets and Systems, 161, 1489-1510.

Xu, R., \& Zhai, X. (2008). Optimal models for single-period supply chain problems with fuzzy demand. Information Sciences, 178, 3374-3381.

Zhou, C., Zhao, R., \& Tang, W. (2008). Supply chain games in a fuzzy environment. Computers \& Industrial Engineering: an international journal, 55, 390-405.

\section{Note}

Note 1. This is an example that has been done in Sazeh Gostar Saipa Company.

Table 1. The EFQM Excellence Model criteria (Carlos, et al., 2009)

\begin{tabular}{|l|l|}
\hline Criterion & Definition \\
\hline Leadership & $\begin{array}{l}\text { Excellent leaders develop and facilitate the achievement of the mission and vision. } \\
\text { They develop organizational values and systems required for sustainable success } \\
\text { and implement these via their actions and behaviors }\end{array}$ \\
\hline Policy and strategy & $\begin{array}{l}\text { Excellent organisations implement their mission and vision by developing a } \\
\text { stakeholder focused strategy that takes account of the market and sector in which } \\
\text { it operates. Policies, plans, objectives and processes are developed and deployed to } \\
\text { deliver strategy }\end{array}$ \\
\hline People & $\begin{array}{l}\text { Excellent organisations manage, develop and release the full potential of their } \\
\text { people at an individual, team-based and organisational level. They promote } \\
\text { fairness and equality and involve and empower their people }\end{array}$ \\
\hline Partnerships and & $\begin{array}{l}\text { Excellent organisations plan to manage external partnerships, suppliers and } \\
\text { internal resources in order to support policy and strategy and the effective } \\
\text { operation of processes }\end{array}$ \\
\hline Processes & $\begin{array}{l}\text { Excellent organisations design, manage and improve processes in order to fully } \\
\text { satisfy, and generate increasing value for, customers and other stakeholders }\end{array}$ \\
\hline Customer results & $\begin{array}{l}\text { Excellent organisations comprehensively measure and achieve outstanding results } \\
\text { with respect to their customers }\end{array}$ \\
\hline People results & $\begin{array}{l}\text { Excellent organisations comprehensively measure and achieve outstanding results } \\
\text { with respect to their people }\end{array}$ \\
\hline Society results & $\begin{array}{l}\text { Excellent organisations comprehensively measure and achieve outstanding results } \\
\text { with respect to society }\end{array}$ \\
\hline $\begin{array}{l}\text { Key performance } \\
\text { results }\end{array}$ & $\begin{array}{l}\text { Excellent organisations comprehensively measure and achieve outstanding results } \\
\text { with respect to the key element of their policy and strategy }\end{array}$ \\
\hline
\end{tabular}


Table 2. Location number for suppliers, manufacture $\&$ distributors

\begin{tabular}{|c|c|c|c|}
\hline Distance ( Km) & Score & Distance ( Km) & Score \\
\hline $0<X<10$ & 100 & $500 \subseteq X<550$ & $45-50$ \\
\hline $10 \leq X \propto 50$ & $95-100$ & $550 \leq X<600$ & $40-45$ \\
\hline $50 \leq X+100$ & $90-95$ & $600 \mathrm{~g} R<650$ & $35-40$ \\
\hline $100 \leq x<150$ & $85-90$ & $650 \mathrm{~g} X<700$ & $30-35$ \\
\hline $150 \leq X<200$ & $80-85$ & $700 \subseteq X<750$ & $25-30$ \\
\hline $200 \leq X<250$ & $75-80$ & $750 \leqq X<800$ & $20-25$ \\
\hline $250 \leq X<300$ & $70-75$ & $800 \mathrm{~g} X<850$ & $15-20$ \\
\hline $300 \leq X<350$ & $65-70$ & $850 \leq X<900$ & $10-15$ \\
\hline $350 \leq X<400$ & $60-65$ & $900 \leq X<950$ & $5-10$ \\
\hline $400 \leq X \times 450$ & $55-60$ & $550 \leq X \propto 1000$ & $1-5$ \\
\hline $450 \leq X \propto 500$ & $50-55$ & $x \geq 1200$ & 1 \\
\hline
\end{tabular}

Table 3. Excellence and location score \& fuzzy capacity of suppliers

\begin{tabular}{|c|c|c|c|}
\hline Capacity & Location score & Excellence score & suppliers \\
\hline$(1517,1614,1810($ & 94 & 290 & 1 \\
\hline$(1381,1414,1460)$ & 75 & 200 & 2 \\
\hline$(1572,1668,1680)$ & 79 & 300 & 3 \\
\hline$(1357,1410,1470)$ & 82 & 280 & 4 \\
\hline$(1900,1960,2000)$ & 61 & 350 & 5 \\
\hline$(1801,1819,1901)$ & 99 & 300 & 6 \\
\hline$(1610,1625,1700)$ & 96 & 310 & 7 \\
\hline$(1185,1270,1402)$ & 76 & 200 & 8 \\
\hline$(1715,1860,1875)$ & 88 & 410 & 9 \\
\hline$(1000,1200,1315)$ & 86 & 240 & 10 \\
\hline$(1500,1561,1670)$ & 90 & 390 & 11 \\
\hline$(1171,1238,1400)$ & 75 & 280 & 12 \\
\hline$(1300,1485,1517)$ & 74 & 190 & 13 \\
\hline$(1615,1762,1815)$ & 100 & 430 & 14 \\
\hline
\end{tabular}


Table 4. Excellence and location score \& fuzzy capacity of manufacturers

\begin{tabular}{|c|c|c|c|}
\hline Capacity & Location score & Excellence score & Manufacturers \\
\hline$(1805,1971,2000)$ & 55 & 380 & 1 \\
\hline$(1712,1834,2025)$ & 63 & 230 & 2 \\
\hline$(1325,1465,1710)$ & 92 & 200 & 3 \\
\hline$(1400,1629,1850)$ & 67 & 220 & 4 \\
\hline$(1100,1286,1450)$ & 82 & 200 & 5 \\
\hline$(954,1054,1220)$ & 77 & 290 & 6 \\
\hline$(1300,1413,1510)$ & 78 & 300 & 7 \\
\hline$(1400,1654,1815)$ & 68 & 230 & 8 \\
\hline$(1250,1488,1513)$ & 69 & 280 & 9 \\
\hline$(1110,1282,1400)$ & 69 & 190 & 10 \\
\hline$(1375,1524,1700)$ & 71 & 240 & 11 \\
\hline$(1120,1346,1500)$ & 67 & 200 & 12 \\
\hline$(1075,1474,1665)$ & 71 & 360 & 13 \\
\hline$(1060,1140,1275)$ & 76 & 240 & 14 \\
\hline$(1620,1827,2025)$ & 80 & 320 & 15 \\
\hline$(1650,1775,1812)$ & 79 & 260 & 16 \\
\hline$(1820,1923,2012)$ & 69 & 260 & 17 \\
\hline$(1235,1445,1620)$ & 91 & 360 & 19 \\
\hline$(1720,1891,2025)$ & 97 & 300 & 20 \\
\hline$(1150,1271,1400)$ & 83 & 270 & 19 \\
\hline
\end{tabular}

Table 5. Excellence and location score \& fuzzy demand of distributors

\begin{tabular}{|c|c|c|c|}
\hline Demand & Location score & Excellence score & Distributors \\
\hline$(2500,2604,2700)$ & 69 & 310 & 1 \\
\hline$(2300,2498,2650)$ & 65 & 240 & 2 \\
\hline$(2520,2614,2710)$ & 87 & 380 & 3 \\
\hline$(2564,2817,3000)$ & 69 & 260 & 4 \\
\hline$(2720,2900,3000)$ & 65 & 400 & 5 \\
\hline$(2125,2364,2400)$ & 98 & 250 & 6 \\
\hline$(2750,2832,2920)$ & 68 & 190 & 7 \\
\hline$(2500,2639,2700)$ & 97 & 350 & 8 \\
\hline$(2100,2200,2350)$ & 92 & 300 & 9 \\
\hline$(2100,2262,2400)$ & 83 & 270 & 10 \\
\hline$(2025,2211,2325)$ & 80 & 260 & 11 \\
\hline$(2000,2094,2220)$ & 92 & 320 & 12 \\
\hline
\end{tabular}


Table 6. Optimal solution of model 2, (S: Supplier, M: Manufacture, D: Distributer)

\begin{tabular}{|c|c|c|c|c|c|c|}
\hline & \multicolumn{2}{|c|}{ M19 } & \multicolumn{2}{|c|}{ M20 } & \multicolumn{2}{|c|}{ D3 } \\
\hline S7 & 10 & --- & 8 & 1273 & -- & --- \\
\hline S9 & 6 & 1202 & 11 & --- & -- & --- \\
\hline M19 & -- & --- & -- & --- & 808 & 1202 \\
\hline M20 & -- & --- & -- & --- & 49 & 1273 \\
\hline
\end{tabular}

ENABLERS

RESULTS

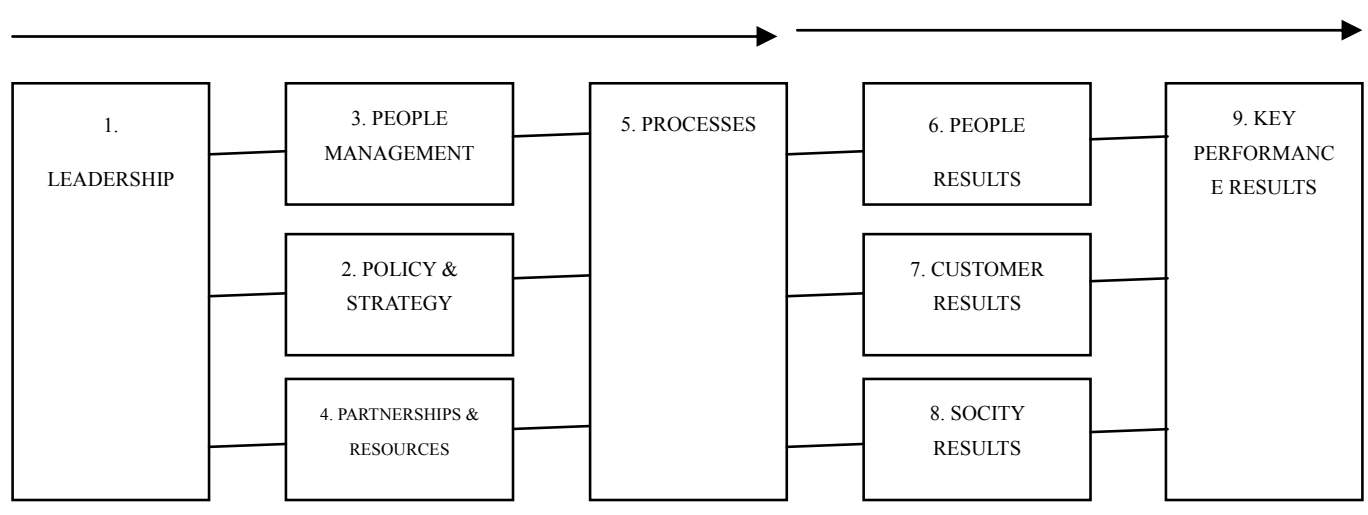

LEARNING \& INNOVATION

Figure 1. The EFQM Excellence Model (2003)

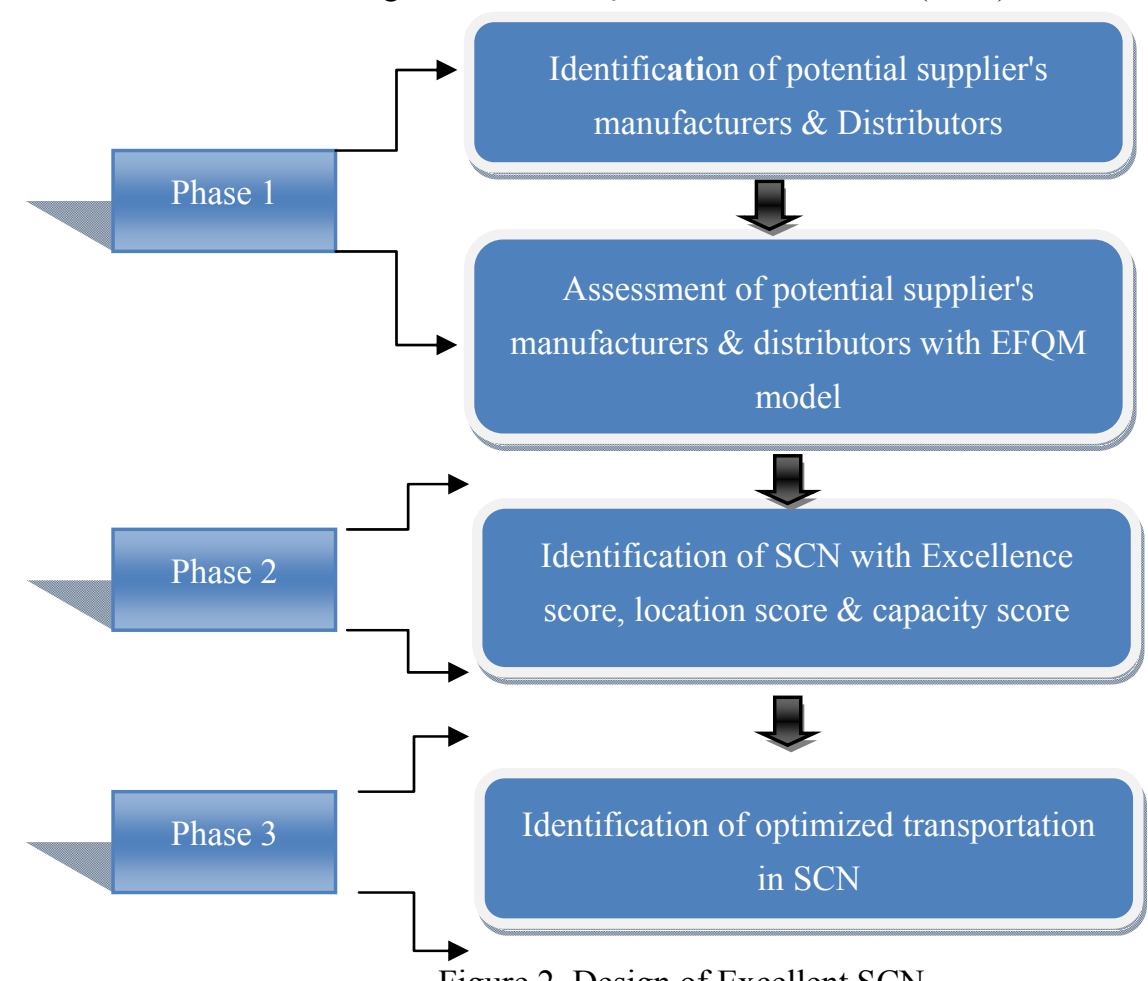

Figure 2. Design of Excellent SCN 


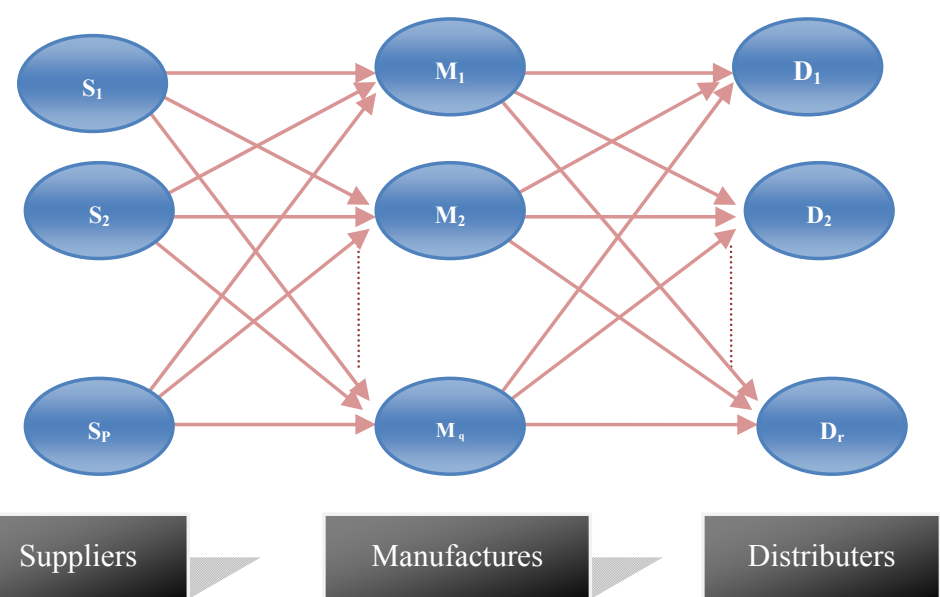

Figure 3. Scenario of transporting parts and materials between suppliers, manufacturers and distributors

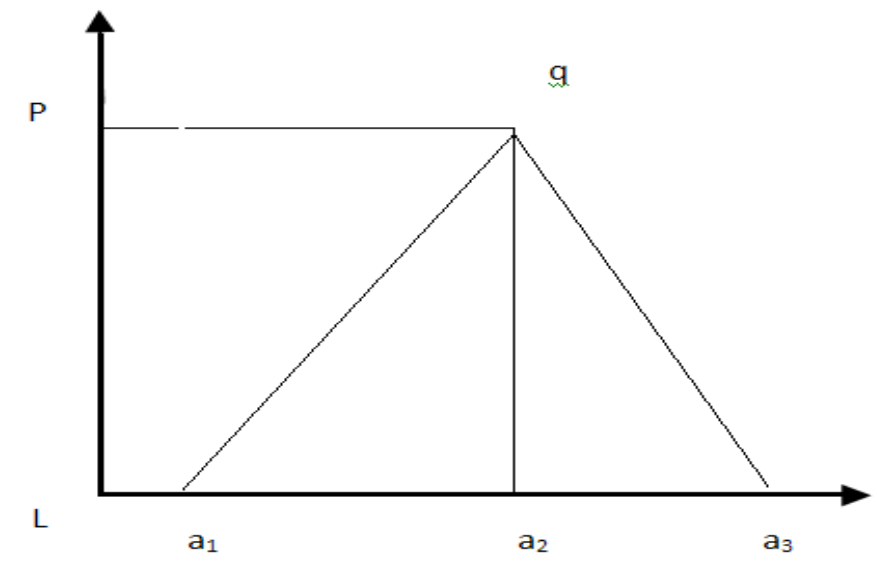

Figure 4. Change fuzzy to crisp 